\title{
Thrombin activatable fibrinolysis inhibitor antigen could not be detected in cerebrospinal fluid
}

\section{Dear Sir,}

The detection of a fibrinolysis inhibitor, thrombin activatable fibrinolysis inhibitor (TAFI), emphasizes the role of thrombin in the down-regulation of fibrinolysis.

TAFI, (also known as procarboxypeptidase U, procarboxypeptidase $\mathrm{B}$ or procarboxypeptidase $\mathrm{R}$ ), is a glycoprotein which is activated by the thrombin/thrombomodulin complex into its active form (TAFIa), a carboxypeptidase B-like enzyme (carboxypeptidase U) (1). It inhibits fibrinolysis by removing carboxyterminal lysine- and arginine residues from partially degraded fibrin, thereby decreasing plasminogen binding on the surface of fibrin (2).

Its plasma concentration has been established as being 4 to 15 $\mathrm{mg} / \mathrm{ml}$ (3) and it has recently also been identified in platelets at a concentration of about $50 \mathrm{ng} / 1 \times 10^{9}$ platelets (4).

As far as we know, there has so far not been any data about the presence ofTAFI in different human body fluids (except in blood - plasma) (5). Since we had previously investigated in one study coagulation abnormalities in different types of brain injury both in plasma and cerebrospinal fluid (CSF), and therefore already had CSF samples, we determined TAFI in CSF.

TAFI antigen was determined using a TAFI-EIA kit from Affinity Biologicals Inc, Ontario, Canada (as previously described (6) in CSF samples obtained from 10 patients with isolated head trauma, from 12 women suffering from idiopathic intracranial hypertension (IIH) and from 12 healthy women. CSF samples were taken from the patients with IIH and healthy women using lumbar puncture. In the patients with head trauma CSF samples were taken from CSF drainage at admission and on day 1,2 and 3. The CSF samples used for TAFI determination were immediately mixed with trisodiumcitrate (ratio 9+1), centrifuged at

Correspondence to:

Jovan P. Antovic, MD, PhD

Coagulation Research

Clinical Chemistry

L25 Karolinska University Hospital

S-I7I 76 Stockholm, Sweden

E-mail: jovanantovic@yahoo.com

Tel.: +468517 79653, Fax: +46831 2428

Received June I, 2004

Accepted after resubmission September 7, 2004

Thromb Haemost 2005; 93: I 78-9
$2000 \mathrm{~g}$ for 20 minutes, then divided into aliquots and frozen at $-70^{\circ} \mathrm{C}$ until test performance.

\section{Results}

Using Affinity Biologicals TAFI-EIA assay and following the recommended assay procedure and dilution of samples 1:200, no TAFI antigen could be detected in the cerebrospinal fluid.

Total TAFI antigen comprises the proenzyme, the active form of the enzyme and its inactive form. The failure to detect TAFI antigen in the CSF, may indicate that the concentration of TAFI antigen in CSF is either very low (much lower than in plasma and under detection limit of used assay), or TAFI antigen is absent from CSF. This could indicate that TAFI does not pass the blood barrier, although the proenzyme, active and inactive forms of the enzyme have relatively low molecular weights, 55 and $35 \mathrm{kD}$, respectively (7). The proenzyme has some affinity for plasminogen and this may prevent its transport into CSF, while it is not entirely clear why the active form and/or inactive form of the enzyme do not pass the blood-brain barrier, although some investigations in mice have shown that the active form of enzyme is in a non-covalent complex with $\alpha 2$-macroglobulin and pregnancy zone protein (9).

The importance of this finding is still unclear. Brain tissue is rich in tissue factor (TF), which has also been found in CSF (10). TF may activate coagulation in patients with different brain pathology and lead to both systemic and local thrombin generation (11). Lack of TAFI in CSF could prevent down-regulation of local fibrinolysis and may to some extent protect microvascular and CSF circulation from thrombosis after different types of brain injury.

However, the novel finding of absence of TAFI antigen in CSF could be of some interest for the understanding of hemostatic disturbances in different types of brain injuries.

Jovan P. Antovic', Jan Hannerz', Michael Nekludov',
Margareta Blombäck'
'Karolinska University Hospital \& Institute,
Coagulation Research, Department of Surgical
Sciences, Stockholm, Sweden
${ }^{2}$ Karolinska University Hospital \& Institute,
Department of Neurology, ${ }^{3}$ Department of Neurosurgery,
Stockholm, Sweden

\section{References}

1. Bajzar L, Manuel R, Nesheim ME. Purification and characterization of TAFI, a thrombin activable fibrinolysis inhibitor. J Biol Chem 1995; 270: 1477-84.

2. Wang W, Boffa MB, Bajzar L, et al. A study of the mechanism of inhibition of fibrinolysis by activated thrombin activable fibrinolysis inhibitor. J Biol Chem 1998; 273: 27176-81.
3. Mosnier LO, von dem Borne PA, Meijers JC, et al. Plasma TAFI levels influence the clot lysis time in healthy individuals in the presence of an intact intrinsic pathway of coagulation. Thromb Haemost 1998; 80: 829-35.

4. Mosnier LO, Buijtenhuijs P, Marx PF, et al. Identification of thrombin activatable fibrinolysis inhibitor (TAFI) in human platelets. Blood 2003; 101: 4844-6.
5. Antovic JP. Thrombin activatable fibrinolysis inhibitor (TAFI) a link between coagulation and fibrinolysis. Clin Lab 2003; 49: 475-86.

6. Antovic JP, Yngen M, Östenson CG, et al. Thrombin activatable fibrinolysis inhibitor (TAFI) and hemostatic changes in patients with type I diabetes mellitus with and without microvascular complications Blood Coag Fibrinolysis 2003; 14: 551-6. 
7. Bouma BN, Marx PF, Mosnier LO, et al. Thrombin-activatable fibrinolysis inhibitor (TAFI, plasma procarboxypeptidase $\mathrm{B}$, procarboxypeptidase $\mathrm{R}$, procarboxypeptidase U). Thromb Res 2001; 101: 329-54. 8. Wang W, Hendriks DF, Scharpe SS. Carboxy-peptidase U, a plasma carboxypeptidase with high affinity for plasminogen. J Biol Chem 1994; 269: 15937-44.
9. Valnickova Z, Thogersen I B, Christensen S, et al. Activated human plasma carboxypeptidase B is retained in the blood by binding to $\alpha_{2}$-macroglobulin and pregnancy zone protein. J Biol Chem 1996; 271: $12937-12943$.
10. Fareed J, Callas DD, Hoppensteadt D, et al. Tissue factor antigen levels in various biological fluids. Blood Coagul Fibrinolysis. 1995; 6 (Suppl. 1): S32-6.

11. Suzuki M, Kudo A, Otawara Y, et al. Extrinsic pathway of blood coagulation and thrombin in the cerebrospinal fluid after subarachnoid hemorrhage. Neurosurgery 1999; 44: 487-93.

\section{Detection of prothrombin gene polymorphism at position 20209 (PT20209C/T): Pilot study in a black population in the United Kingdom}

\section{Dear Sir,}

Knowledge of the genetic risk factors underlying venous thrombo-embolism (VTE) in the black population remains sparse (1, $2)$. The two most common genetic variants that predispose to thrombosis (Factor V Leiden and Prothrombin (PT) 20210G/A) occur predominantly in those of European origin and are rare in other ethnic groups (3). Despite this, venous thrombosis has a worldwide prevalence, suggesting that populations of non-European origin possess previously uncharacterised prothrombotic mutations (2). Warshawsky et al have reported a novel C to T mutation occurring one base pair (bp) upstream from the known PT20210G/A polymorphism in four unrelated African-American patients (4). Three of these patients had a history of venous thrombosis or stroke. The polymorphism was absent in 440 individuals from other US ethnic groups including Caucasians, Hispanics, Asians and Native-Americans. The world population distribution and clinical significance of this novel polymorphism remains unclear. As this polymorphism was restricted to African-Americans (most of whom had experienced thromboembolic events), we hypothesised that it might represent a candidate prothrombotic mutation in the UK black population.

We studied a previously reported group of 125 black subjects (5), 61 with a history of deep vein thrombosis (DVT) (27 male and 34 female, mean age 56.2 years, SD 14.6) and 64 healthy controls ( 9 male and 55 female, mean age 55 years, SD 14). All subjects were of African $(28.8 \%)$ or Afro-Caribbean origin (71.2\%) and had negative thrombophilia tests including genotyping for FV Leiden and PT20210A and phenotypic studies for activated protein $\mathrm{C}$ resistance, antithrombin, protein $\mathrm{C}$, free protein $\mathrm{S}$ and lupus anticoagulant. Subjects with hereditary thrombophilia $(9.1 \%)$ were excluded from the study. The control subjects had no known history of VTE or malignancy. Cases had completed a standard course of anticoagulant treatment for objectively confirmed DVT at least 3 months previously. A panel of

\footnotetext{
Correspondence to:

Dr Roopen Arya

Department of Haematological Medicine

King's College Hospital

Denmark Hill, London. SE59RS, UK

Tel. + 442073463570 , Fax: + 44207346 I5 I2

E-mail: roopen.arya@kcl.ac.uk
}

Received September 2, 2004

Accepted after revision October 28, 2004

Thromb Haemost 2005; 93: I79-80
50 healthy Asian Indians and 69 healthy South East Asians were also screened for the presence of this polymorphism. A PCRRFLP based assay that incorporated an invariant digestion site was developed for detection of the PT20209C/T polymorphism (Fig. 1A).

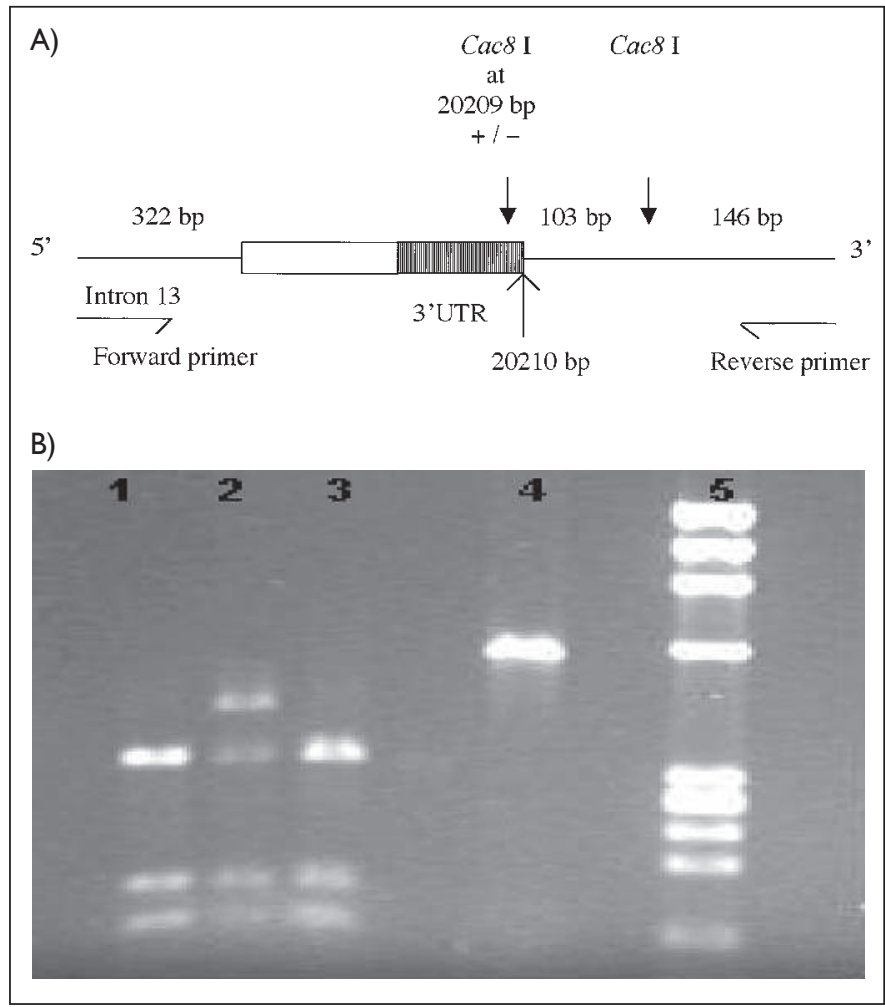

Figure I: PCR-RFLP based assay for detection of the PT20209C/T polymorphism. A: The terminal exon (exon 14) including the 3' untranslated region (3'UTR) (hatch box) of the prothrombin gene is amplified by PCR. Presence of the T variant at position 20209 of the prothrombin gene removes a cutting site for Cac8 I. An invariant Cac8 I cutting site acts as a control for complete digestion of the PCR product. Hence, Cac8 I restriction analysis of wild type will produce 3 fragments of $322 \mathrm{bp}, 103 \mathrm{bp}$ and $146 \mathrm{bp}$; homozygotes for prothrombin C20209T will produce 425 bp and I 46 bp while C20209T heterozygotes will produce 4 DNA fragments of 425 bp, 322 bp, I 03 bp and I 46 bp. B. Agarose gel electrophoresis of PCR products after an overnight digestion with $\mathrm{Cac} 8 \mathrm{I}$ at $37^{\circ} \mathrm{C}$. Lanes I and 3 represent wild type prothrombin gene; lane 2 heterozygote for prothrombin C20209T; lane 4 uncut PCR product and lane 5 DNA molecular marker $\phi$ XI74-Hae III. 